\title{
ANALISIS PENDAPATAN PETANI KAKAO DI DESA SOE KECAMATAN PAMONA PUSELEMBA
}

\section{The Analysis of Cacao Farming Income at Soe Village Pamona Puselemba Distric}

\author{
Nurfhin Ilma Bunga \\ Fakultas Pertanian Universitas Kristen Tentena \\ Jl.Torulemba No.21 Tentena, Poso, Sulawesi Tengah \\ e-mail : nbunga89@gmail.com
}

\begin{abstract}
Abstrak
Penelitian ini bertujuan untuk menganalisis biaya, pendapatan dan kelayakan usaha tani kakao di Desa Soe. Penelitian ini dilakukan di Desa Soe Kecamatan Pamona Puselemba Kabupaten Poso pada bulan Agustus-Oktober 2016. Data primer diperoleh dari hasil survey dan wawancara menggunakan kuisioner terhadap 23 petani sebagai responden dan data sekunder diperoleh dari literatur dan lembaga/instansi terkait. Analisis data yang digunakan adalah analisis pendapatan usaha tani. Hasil penelitian menunjukan bahwa rata-rata penerimaan usaha tani kakao di Desa Soe adalah sebesar $R p$ 7.391.037,13/Ha dengan rata-rata biaya produksi usaha tani sebesar $R p$ 1.060.460,95 dan rata-rata pendapatan/ha sebesar $R p$ 6.330.576,18. 2. Nilai kelayakan usaha tani kakao sebesar 6,97 menunjukan bahwa usaha tani kakao di Desa So'e layak untuk diusahakan. Usaha tani kakao di Desa Soe dapat memberikan sumbangan pendapatan bagi petani walaupun dengan keuntungan yang belum optimal. Sebaiknya ada kebijakan pemerintah terkait penggunaan teknologi khususnya teknologi panen dan pascapanen seperti mesin pengupas kulit kakao sehingga petani dapat mengurangi dan meminimalisir biaya tenaga kerja.
\end{abstract}

Kata kunci : Usaha Tani Kakao, Pendapatan

\begin{abstract}
This research aims at analyzing cost, income, and eligibility of cacao farming at Soe Village. Study was conducted at Soe Village Pamona Puselemba District Poso Regency in August to October 2016. Primary data was obtained from survey result and interview using questionnaire to 23 farmers as respondents, whereas secondary data was taken from literatures and related institutions. Income analysis was used to analyze data. Study result indicate that the average revenue of cacao farming at Soe Village is as many as $R p$ 7,391,037.13/ha,average farming cost production is $R p$ $1,060,460.95 / \mathrm{h}$ a, and average income is as many as $R p$ 6,330,576.18/ha. The value of cacao eligibility as many as 6.97 demonstrates that cacao farming at Soe Village is eligible to perform. Cacao farming at Soe Village can contribute as the source of income for farmers although the profit is not optimal yet. It is recommended that government support policies associated to technology application, particulary harvest and post-harvest technologies such as peeling machines so that farmers will be able to reduce and to minimize the labor costs.
\end{abstract}

Kata kunci : cacao farming, income

\section{PENDAhULUAN}

Usaha tani merupakan cara-cara menentukan, mengorganisasikan dan mengkordinasi penggunaan faktor-faktor produksi seefektif dan seefisien mungkin sehingga usaha tersebut memberikan pendapatan semaksimal mungkin (Suratiyah, 2008). Hasil penelitian Nurdiansyah (2015) di 
Kecamatan Sekampung Udik Kabupaten Lampung Timur menunjukan bahwa usaha tani kakao menguntungkan bagi petani dengan jumlah pendapatan sebesar $\mathrm{Rp}$ 8.968.815,30. Dengan nilai R/C rasio sebesar 2,32 yang menunjukan bahwa usaha tani kakao layak diusahakan.

Di Indonesia terdapat 5 sektor pertanian yang diusahakan oleh masyarakat tani yaitu sektor tanaman pangan, perkebunan, kehutanan, perikanan, dan peternakan yang diharapkan mampu meningkatkan produksi pertanian dan pendapatan petani. Komoditi sektor tanaman perkebunan yang diusahakan oleh masyarakat Indonesia salah satunya adalah tanaman kakao. Kakao masih tergolong komoditi yang sangat penting di Indonesia,berdasarkan data Kementrian Perindustrian, 2016 menyebutkan bahwa, kebutuhan kakao dalam negeri mencapai 800.000 ton/tahun sedangkan produksi kakao di Indonesia belum dapat memenuhi kebutuhan tersebut. Petani kakao di Indonesia hanya mampu memproduksi kakao sekitar 300.000 ton/tahun, sehingga untuk memenuhi kebutuhan tersebut pemerintah harus mengimpor kakao. Produksi kakao dalam negeri mengalami penurunan. Ditahun 2016 produksi kakao hanya 315.000 ton, dan diprediksi pada tahun 2017 akan mengalami penurunan menjadi 300.000 ton.

Kabupaten Poso merupakan salah satu daerah yang sebagian masyarakatnya mengusahakan usaha tani kakao. Untuk kabupaten Poso luas lahan tanaman kakao sebesar 39.104 ha dengan produksi sebesar 18.649 ton dan merupakan luas tanam terbesar jika dibandigkan dengan luas tanam komoditi lainnya. (BPS Kab.Poso, 2016). Desa Soe merupakan salah satu desa yang berada di wilayah kabupaten Poso tepatnya di Kecamatan Pamona Puselemba dan sebagian masyarakatnya bermata pencaharian sebagai petani. Usahatani kakao di desa Soe merupakan perkebunan rakyat karena diusahakan dan dikelola oleh petani itu sendiri. Dalam kegiatan usahatani tersebut, petani tidak mengetahui secara pasti berapa keuntungan dan biaya yang dikeluarkan selama proses produksi.Oleh karena itu diperlukan penelitian terhadap usahatani kakao yang dilakukan oleh petani khususnya di Desa Soe guna untuk peningkatan pendapatan petani kakao dan produksi kakao.
Adapun penelitian ini bertujuan untuk untuk menganalisis biaya, pendapatan dan kelayakan usaha tani di Desa Soe.

\section{METODEPENELITIAN}

\section{Waktu dan Lokasi Penelitian}

Penelitian ini dilaksanakan di Desa So'e Kecamatan Pamona Puselemba Kabupaten Poso Sulawesi Tengah pada bulan FebruariApril 2016.

\section{Teknik Pengambilan Sampel}

Teknik pengambilan sampel adalah dengan menggunakan teknik purposive sampling yaitu berdasarkan pertimbangan khusus, yaitu petani kakao dengan jumlah responden sebanyak 23 petani kakao.

\section{Jenis dan Sumber Data}

Data yang digunakan dalam penelitian ini adalah data primer dan data sekunder. Data primer diperoleh dari petani kakao sebagai responden melalui teknik wawancara dengan menggunakan kuisioner yang telah dipersiapkan. Data sekunder diperoleh dari literatur dan lembaga/instansi terkait.

\section{Analisis data}

Untuk mengetahui jumlah pendapatan petani kakao, data yang diperoleh dianalisis dengan menggunakan rumus :

$$
\begin{array}{ll}
\text { I } & =\text { TR }- \text { TC } \\
\text { TR } & =\mathbf{Q} \times \text { Pq } \\
\text { TC } & =\text { TVC }+ \text { TFC }
\end{array}
$$

Keterangan :

$$
\begin{array}{ll}
\mathrm{I} & =\text { Pendapatan (Income) } \\
\mathrm{TR} & =\text { Total Penerimaan }(\text { Total Revenue) } \\
\mathrm{TC} & =\text { Biaya Total }(\text { Total Cost) } \\
\mathrm{Q} & =\text { Jumlah Produksi Kakao }(\mathrm{kg}) \\
\mathrm{Pq} & =\text { Harga per Kg Kakao }(\mathrm{Rp}) \\
\mathrm{TVC} & =\text { Total Variabel Cost/Total Biaya } \\
& \text { Variabel (Rp) } \\
\mathrm{TF} & =\text { Total Fixed Cost / Total BiayaTetap } \\
& (\mathrm{Rp})
\end{array}
$$

(Soekartawi, 2006)

Untuk kelayakan usaha tani, maka digunakan rumus analisis Return Cost Ratio :

$$
\mathrm{R} / \mathrm{C}=\frac{\mathrm{TR}}{\mathrm{TC}}
$$


Keterangan :

$\mathrm{TR}=$ Total Revenue (penerimaaan total)

$\mathrm{TC}=$ Total Cost $($ biaya total $)$

Pengambilan keputusan adalah :

a. Jika $\mathrm{R} / \mathrm{C}>1$, maka usaha tani yang dilakukan menguntungkan, karena penerimaan lebih besar dari biaya total.

b. Jika $\mathrm{R} / \mathrm{C}<1$, maka usaha tani yang dilakukan tidak menguntungkan, karena penerimaan lebih kecil daripada biaya total.

c. Jika $\mathrm{R} / \mathrm{C}=1$, maka usaha tani yang di lakukan tidak menguntungkan dan tidak

Tabel 1. Umur Petani Kakao di Desa So'e juga merugi ( impas ), karena penerimaan total sama dengan biaya total.

\section{HASIL DAN PEMBAHASAN}

\section{Karaktristik Responden}

Karakteristik responden dalam penelitian ini meliputi umur, jenis kelamin, dan pendidikan.

\section{Umur}

Distribusi umur responden berkisar antara $30-66$ tahun. Distribusi umur responden dapat dilihat pada tabel 1.

\begin{tabular}{|l|r|r|}
\hline \multicolumn{1}{|c|}{ UMUR (TAHUN) } & JUMLAH & \multicolumn{2}{|c|}{$\%$} \\
\hline$<30$ & 0 & 0.00 \\
\hline $30-40$ & 4 & 17.39 \\
\hline $41-50$ & 12 & 52.17 \\
\hline$<50$ & 7 & 30.43 \\
\hline JUMLAH & $\mathbf{2 3}$ & $\mathbf{1 0 0}$ \\
\hline
\end{tabular}

Sumber : Data Primer, 2016

Dari data diatas dapat dilihat bahwa sebagian besar petani kakao berada pada usia produktif yaitu 41-50 tahun sebesar $52.17 \%$.

\section{Jenis Kelamin}

Sebagian besar petani kakao di desa

So'e adalah laki-laki, namun ada juga petani kakao yang berjenis kelamin perempuan. Jenis kelamin petani kakao di desa So'e adalah sebagai berikut.

Tabel 2. Jenis Kelamin Petani Kakao

\begin{tabular}{|l|r|r|}
\hline \multicolumn{1}{|c|}{ JENIS KELAMIN } & JUMLAH & \multicolumn{2}{|c|}{$\%$} \\
\hline PEREMPUAN & 2 & 9 \\
\hline LAKI-LAKI & 21 & 91 \\
\hline JUMLAH & $\mathbf{2 3}$ & $\mathbf{1 0 0}$ \\
\hline
\end{tabular}

Sumber : Data Primer, 2016

Berdasarkan data diatas dapat diketahui bahwa jenis kelamin petani kakao laki-laki sebesar $91 \%$ dan petani kakao berjenis kelamin perempuan sebesar 9\%. Sebagian besar yang menjadi petani kakao adalah lakilaki dan cocok dikerjakan untuk laki-laki karena membutuhkan tenaga yang besar dan kuat jika dibandingkan dengan perempuan.

\section{Pendidikan}

Pendidikan formal yang diperoleh petani kakao di Desa Soe berbeda-beda ada yang hanya tamatan SD, SMP, SMA bahkan perguruan tinggi. Tingkat pendidikan petani di Desa So'e dapat dilihat di tabel berikut. 
Tabel 3. Tingkat Pendidikan Petani di Desa Soe

\begin{tabular}{|l|r|r|}
\hline \multicolumn{1}{|c|}{ PENDIDIKAN } & JUMLAH & \% \\
\hline SD & 4 & 17 \\
\hline SMP & 4 & 17 \\
\hline SMA & 12 & 52 \\
\hline & 3 & 13 \\
\hline JUMLAH & $\mathbf{2 3}$ & $\mathbf{1 0 0}$ \\
\hline
\end{tabular}

Sumber : Data Primer, 2016

Berdasarkan tabel diatas diketahui bahwa semua petani kakao telah mengenyam pendidikan. Sebagian besar petani berpendidikan SMA yaitu 52\%, SMP 17\%, SMA $17 \%$ dan tidak berpendidikan sebesar $13 \%$.

\section{Biaya Produksi Usaha Tani Kakao}

Biaya usaha tani merupakan biaya yang benar-benar dikeluarkan petani untuk membiayai usaha taninya yang meliputi biaya sarana produksi, tenaga kerja, dan lain-lain. Dari tabel 4 dapat dilihat bahwa rata-rata biaya sarana produksi per usaha tani adalah sebesar Rp 1.800.478,26,- dengan pengeluaran terbesar terdapat pada tenaga kerja yaitu dengan jumlah rata-rata $\mathrm{Rp}$ 874.782.61,-- kemudian diikuti dengan biaya penggunaan pupuk sebesar Rp 672.826,09,dan penggunaan pestisida sebesar $\mathrm{Rp}$
252.869,57,-. Biaya tenaga kerja merupakan komponen biaya terbesar dalam usaha tani kakao di Desa So'e hal ini disebabkan dalam proses produksi, baik pemeliharaan maupun panen para petani kakao masih menggunakan tenaga manusia dan peralatan sederhana dengan luas lahan kakao yang diusahakan rata-rata sebesar 1,69 ha untuk masingmasing petani kakao. Upah tenaga kerja harian berkisar antara Rp 60.000-Rp70.000. Untuk meningkatkan produksi dan membasmi hama pada kakao petani menggunakan beberapa jenis pupuk antara lain Urea, Phonska, Npk dan Kcl dan pestisida yang digunakan antara lain Kiss Up, Sidometri, Alika, Bio-Up, Puradan dan Gramazon. Petani tidak banyak menggunakan banyak biaya untuk pembelian pestisida karena hama dan penyakit yang menyerang tidak begitu banyak.

Tabel 4. Rata-Rata Biaya Produksi Pada Usahatani Kakao di Desa Soe

\begin{tabular}{|clrr|}
\hline No. & \multicolumn{1}{|c}{ Uraian } & $\begin{array}{c}\text { Total Biaya Per Usaha Tani } \\
(\mathbf{R p})\end{array}$ & $\begin{array}{c}\text { Rata-Rata Biaya Per } \\
\text { Usaha Tani (Rp) }\end{array}$ \\
\hline $\mathbf{1}$ & $\begin{array}{l}\text { Penggunaan pupuk } \\
\text { (Urea,Phonska,Npk,Kcl) }\end{array}$ & 15.475 .000 & $672.826,09$ \\
\hline $\mathbf{2}$ & Penggunaan pestisida & 5.816 .000 & $252.869,57$ \\
\hline $\mathbf{3}$ & HOK/Tenaga Kerja & 20.120 .000 & $874.782,61$ \\
\hline & JUMLAH & $\mathbf{4 1 . 4 1 1 . 0 0 0}$ & $\mathbf{1 . 8 0 0 . 4 7 8 , 2 6 1}$ \\
\hline
\end{tabular}

Sumber : Data Primer, 2016

Tabel 5. Rata-Rata Biaya Produksi Pada Usahatani Kakao di Desa Soe

\begin{tabular}{|clrr|}
\hline No. & \multicolumn{1}{c}{ Uraian } & $\begin{array}{c}\text { Total Biaya Per Usaha Tani } \\
(\mathbf{R p})\end{array}$ & $\begin{array}{c}\text { Rata-Rata Biaya Per } \\
\text { Hektar } \\
(\mathbf{R p})\end{array}$ \\
\hline $\mathbf{1}$ & $\begin{array}{l}\text { Penggunaan pupuk } \\
\text { (Urea,Phonska,Npk,Kcl) }\end{array}$ & 15.475 .000 & $396.286,81$ \\
\hline $\mathbf{2}$ & Penggunaan pestisida & 5.816 .000 & $148.937,26$ \\
\hline $\mathbf{3}$ & HOK/Tenaga Kerja & 20.120 .000 & $515.236,88$ \\
\hline & JUMLAH & $\mathbf{4 1 . 4 1 1 . 0 0 0}$ & $\mathbf{1 . 0 6 0 . 4 6 0 , 9 5}$ \\
\hline
\end{tabular}

Sumber : Data Primer, 2016 


\section{Penerimaan}

Penerimaan usaha tani kakao merupakan perkalian antara jumlah produksi kakao dikalikan dengan harga jual kakao. Dari tabel 6. Dapat dilihat total penerimaan usaha tani kakao di Desa So'e dalam sekali musim panen sebesar Rp 288.620.000,-dengan penerimaan rata-rata sebesar $\mathrm{Rp}$ 12.548.695,65-. Penerimaan per hektar sebesar Rp 7. 391.037,13.

Tabel 6. Penerimaan Usaha Tani Kakao di Desa Soe

\begin{tabular}{rlrrr} 
No & \multicolumn{1}{c}{ Uraian } & $\begin{array}{c}\text { Total Penerimaan } \\
\text { Per Usaha Tani }\end{array}$ & $\begin{array}{c}\text { Rata-Rata } \\
\text { Penerimaan Per } \\
\text { Usaha Tani }\end{array}$ & $\begin{array}{c}\text { Rata-Rata Penerimaan } \\
\text { Per Hektar }\end{array}$ \\
\hline 1 & Produksi (Kg) & 9205.00 & 400,22 & 235,72 \\
2 & Harga Produksi (Rp/Kg) & $25.000-37.000$ & $30.391,30$ & $30.391,30$ \\
3 & Penerimaan & 288.620 .000 & $12.548 .695,65$ & $7.391 .037,132$ \\
\hline
\end{tabular}

Sumber : Data Primer, 2016

\section{Pendapatan dan Kelayakan Usaha Tani Kakao}

Pendapatan bersih atau keuntungan adalah perbedaan atau selisih antara pendapatan kotor (gross income) atau penerimaan dan biaya operasi (operatingcost).

Pendapatan usaha tani kakao di Desa So'e sebesar Rp 247,209,000,- dengan pendapatan rata-rata sebesar $\mathrm{Rp} 10.748 .217,-$.Total produksi kakao di Desa So'e dalam sekali musim panen yaitu $9.205 \mathrm{~kg}$ dengan produksi rata-rata 400,22 kg. Sedangkan untuk pendapatan per ha yaitu sebesar Rp 6.330.576 . Pendapatan usaha tani kakao di Desa So'e dapat dilihat pada tabel 7.

\section{Tabel 7. Rata-Rata Pendapatan Usahatani Kakao}

\begin{tabular}{rlrr}
\hline No & \multicolumn{1}{c}{ Uraian } & $\begin{array}{c}\text { Rata-Rata Pendapatan } \\
\text { Per Usaha Tani } \\
\text { (Rp) }\end{array}$ & $\begin{array}{c}\text { Rata-Rata } \\
\text { Pendapatan Per } \\
\text { Hektar (Rp) }\end{array}$ \\
\cline { 3 - 4 } 1 & Penerimaan Usaha Tani & $12.548 .695,65$ & $7.391 .037,13$ \\
2 & Biaya Produksi Usaha Tani & $1.800 .478,26$ & $1.060 .460,95$ \\
3 & Pendapatan Usaha Tani & $10.748 .217,39$ & $6.330 .576,18$ \\
4 & R/C & 6,97 & 6,97 \\
\hline
\end{tabular}

Sumber : Data Primer, 2016

Pendapatan yang diperoleh petani secara keseluruhan digunakan petani untuk memenuhi kebutuhan hidup sehari-hari dan juga digunakan untuk memodali kembali proses produksi usaha tani para petani kakao. Hal serupa juga terjadi Desa Dangia, Kec. Ladongi, Kab. Kolaka Sulawesi Tenggara, berdasarkan hasil penelitian Ermiati $d k k$ ( 2014) menunjukan bahwa usaha tani kakao dapat memberikan sumbangan pendapatan kepada petani walaupun dengan keuntungan yang belum optimal dan masih dinilai layak dan menguntungkan untuk diusahakan. Untuk kelayakan usaha tani kakao di desa So'e, berdasarkan hasil analisis $\mathrm{R} / \mathrm{C}$ yaitu sebesar
$6,97>1$, yang secara teori menjelaskan bahwa usaha tani menguntungkan karena penerimaan lebih besar dari biaya total. Setiap 1 rupiah biaya yang dikeluarkan dalam usahatani kakao akan diperoleh penerimaan sebesar 6,97 rupiah.

\section{KESIMPULAN DAN SARAN}

\section{Kesimpulan}

1. Usaha tani kakao di Desa Soe dapat memberikan sumbangan pendapatan bagi petani walaupun dengan keuntungan yang belum optimal. Rata-rata penerimaan usahatani kakao di Desa So'e sebesar Rp 
7.391.037,13/ha, rata-rata biaya produksi usaha tani sebesar Rp 1.060.460,95/ha dan rata-rata pendapatan/ha sebesar $\mathrm{Rp}$ $6.330 .576,18 / \mathrm{ha}$

2. Nilai kelayakan usaha tani kakao sebesar 6,97 menunjukan bahwa usaha tani kakao di Desa So'e layak untuk diusahakan.

Saran

Sebaiknya ada kebijakan pemerintah terkait penggunaan teknologi khususnya teknologi panen dan pascapanen seperti mesin pengupas kulit kakao sehingga petani dapat mengurangi dan meminimalisir biaya tenaga kerja.

\section{REFERENSI}

BPS Poso, 2016. Kabupaten Poso Dalam Angka 2016. Badan Pusat Statistik, Kabupaten Poso, Poso

Direktorat Jendral Industri Agro. 2016. 2016 Produksi Kakao Capai 300 RibuTon. http://agro.kemenperin.go.id/52082018,-Produksi-Kakao-Capai-300Ribu-Ton .
Ermiati, $d k k$. 2014. Profil dan Kelayakan Usahatani Kakao di Kabupaten Kolaka, Sulawesi Tenggara.J. TIDP 1(3): 125-132.

Nurdiansyah, A. 2015. Analisis Pendapatan dan Pemasaran Kakao di Kecamatan Sekampung Udik Kabupaten Lampung Timur. Skripsi. Fakultas Pertanian, Universitas Lampung, Bandar Lampung.

Soekartawi, 2006. Analisis Usaha Tani. UI Press. Jakarta

Suratiyah, Ken. 2008. Ilmu Usaha Tani. Penebar Swadaya, Jakarta. 